\title{
The relationships between dietary $\alpha$-linolenic:linoleic acid and rat platelet eicosapentaenoic and arachidonic acids
}

\author{
BY ELIZABETH A. LEECE AND MARGARET A. ALLMAN* \\ Human Nutrition Unit, Department of Biochemistry, University of Sydney, NSW, 2006, Australia
}

(Received 8 June 1995 - Revised 24 January 1996-Accepted 26 January 1996)

\begin{abstract}
Increased dietary intake of $\alpha$-linolenic acid (ALA) may be desirable to enrich tissue eicosapentaenoic acid (EPA; 20:5n-3) but competition between $n-3$ and $n-6$ fatty acids for enzymes involved in elongation and subsequent acylation will determine the relative proportions of phospholipid fatty acids. The aim of the present study was to examine the effects of altering the dietary ALA: linoleic acid (LA) ratio on rat platelet EPA and arachidonic acid (AA; 20:4n-6) concentrations. Sprague-Dawley rats were fed on diets containing $30 \%$ total energy as fat with approximately $10 \%$ each of saturated, monounsaturated and polyunsaturated fatty acids with one of the following ALA:LA values; 1:7, 1:4, 1:1 or 1.3:1 (nine rats per group). After 4 weeks, blood was withdrawn from the abdominal aorta and platelet fatty acids analysed. The proportion of EPA was greater at the $1: 1$ and 1:3:1 ratios compared with the $1: 7$ and $1: 4$ $(P<0.05)$, and a decrease in $A A$ was observed $(P<0.05)$ at the higher ratios. It was established that the platelet EPA:AA value increased $(P<0.05)$ as the dietary ALA:LA value increased.
\end{abstract}

$\alpha$-Linolenic acid:linoleic acid ratio: Eicosapentaenoic acid: Arachidonic acid: Rat platelets

It appears desirable to increase the eicosapentaenoic acid (EPA; 20:5n-3): arachidonic acid (AA; 20:4n-6) ratio in membrane phospholipids. Both these $\mathrm{C} 20$ fatty acids are substrates for production of eicosanoids, e.g. thromboxane and leukotrienes (Herold \& Kinsella, 1986). EPA results in eicosanoids which are less aggregatory and inflammatory than those from AA and may lessen the tendency to thrombosis and atherosclerosis (Dyerberg et al. 1978; Terano et al. 1986). In Western diets the predominant polyunsaturated fatty acid is linoleic acid (LA; 18:2n-6) (Truswell et al. 1992) which is elongated to AA (de Gomez Dumm \& Brenner 1975). The corresponding $n$-3 fatty acid, $\alpha$-linolenic acid (ALA; $18: 3 n$ 3 ) is converted to EPA via the same enzymic pathways. Recent work confirms that the replacement of some LA with ALA may increase tissue EPA via its elongation (Renaud \& Nordoy, 1983; Sanders \& Roshani, 1983; Weaver et al. 1990; Mantzioris et al. 1995) but the efficiency of this conversion in man was previously questioned (Dyerberg et al. 1983). ALA is preferred to LA as substrate of $\Delta-6$ desaturase (Emken et al. 1992) but AA is favoured over EPA as a substrate for acylation into phospholipids (Emken et al. 1992). Feeding EPA and by-passing the conversion step is obviously a more efficient way to increase tissue EPA but while habitual consumption of fatty fish will increase it and decrease AA, it may not be feasible to increase fish consumption for all people on a global basis. Therefore the use of ALA to increase tissue EPA warrants research.

The doses of ALA that have been used in previous studies have varied, as has the subsequent phospholipid enrichment. It appears that it is the $n-3: n-6$ fatty acid ratio, in particular ALA:LA, rather than the absolute amount of ALA which influences the incorporation. Increases in ALA:LA from 1:170 through to $1: 4,1: 2$ and $1: 1$ were associated with increasing percentages of EPA in rat plasma, lung and liver phospholipids

* For reprints. 
(Hwang et al. 1988) while increases in the amount of ALA but with constant ALA : LA ratio produced no differences (Boudreau et al. 1991). Chan et al. (1993) reported that in men an ALA: LA value of $1: 3$ increased platelet EPA compared with $1: 27$ and $1: 7$, and that if the quantity of ALA was doubled while the ratio was kept constant no further increases occurred. Further confirmation that the ALA:LA ratio is important was provided by Emken et al. (1993) who found that the conversion of ALA to longer-chain metabolites, measured after infusions of deuterated ALA and LA, was reduced by $30 \%$ after feeding a diet with $29 \cdot 8 \mathrm{~g}$ LA $v .15 \cdot 1 \mathrm{~g} \mathrm{LA}$.

The present study was designed to extend previous studies. The rat studies in which the dietary ALA: LA ratio has been controlled have measured fatty acids in tissues other than platelets (Hwang et al. 1988; Lands et al. 1990). The dietary values of ALA:LA in the current study have been selected because they would be achievable in human mixed diets based on $30 \%$ total energy from fat with $10 \%$ energy from saturated fat and $10 \%$ energy from polyunsaturated fat. Previous studies have not been concerned with this. We would have preferred to study humans but with free-living conditions it is impossible to be certain that subjects have complied with the exact ratio. The rat provides a reasonable model because it has the same enzyme pathways as humans for elongation and desaturation of ALA to EPA (de Gomez Dumm \& Brenner 1975; Crawford et al. 1976).

\section{METHODS}

\section{Animals and diets}

Forty-five Sprague-Dawley specific-pathogen-free rats ( 8 weeks old) were fed on diets with varying ALA: LA ratios of $1: 7,1: 4,1: 1$ and $1 \cdot 3: 1$ based on weight. Rats were housed in cages (three per cage) kept in a room at constant temperature $\left(25^{\circ}\right)$ with a $12 \mathrm{~h} \mathrm{light-dark}$ cycle maintained. The animals were maintained on standard rat chow for 1 week (YS Feeds, Mouse Breeder, Young, NSW, Australia), ratio 1:12, until commencement of the modified diets which were fed for 4 weeks.

The diets were identical in macronutrients, i.e. $191 \mathrm{~g}$ protein $/ \mathrm{kg}, 678 \mathrm{~g}$ carbohydrate $/ \mathrm{kg}$, $35 \mathrm{~g}$ fibre $/ \mathrm{kg}$ and $131 \mathrm{~g}$ fat $/ \mathrm{kg}$ feed, and had the same vitamin and mineral content, the only exception being the contribution of the oils to vitamin E. The amounts of saturated, monounsaturated and polyunsaturated fatty acids were similar. The fatty acid compositions of the diets determined using GC are shown in Table 1. Palm olein, palm stearin, sunflowerseed oil, rapeseed oil (EOI Foods Pty Ltd, Marrickville, NSW, Australia) and linseed oil (Melrose foods, Box Hill, Victoria, Australia) were mixed in various amounts to achieve the desired fat composition and the ALA:LA values. Animals had free access to feed. Fresh feed was put in each cage every weekday morning and enough for $2 \mathrm{~d}$ was placed on late Friday afternoon.

The study was approved by the Animal Care and Ethics Committee of the University of Sydney.

\section{Blood collection}

At the end of the 4 weeks feed was withheld overnight and the rats were anaesthetized with diethyl ether, used in a manner which prevented irritation of mucous membranes. After incision, blood was collected from the abdominal aorta of each rat, using a $23 \mathrm{G}$ needle (Becton Dickinson, Singapore) and plastic syringes to which $1 \mathrm{ml}$ of sodium citrate $(38 \mathrm{~g} / \mathrm{l})$ had been added. Platelet-rich-plasma (PRP) was made by centrifuging the blood for $10 \mathrm{~min}$ at $119 \mathrm{~g}\left(25^{\circ}\right)$. The PRP from three rats was pooled and centrifuged at $1000 \mathrm{~g}$ for $10 \mathrm{~min}$ to pellet the platelets. The resultant platelet pellet was washed three times in $2 \mathrm{ml} \mathrm{Ca}{ }^{2+}$-free Tyrode's solution (137 mm-NaCl, $12 \mathrm{~mm}-\mathrm{NaHCO}, 2.7 \mathrm{~mm}-\mathrm{KCl}, 0.4 \mathrm{~mm}-\mathrm{NaH}_{2} \mathrm{PO}_{4}$ and 
Table 1. Fatty acid composition of the diets ( $\mathrm{g} / 100 \mathrm{~g}$ total fatty acids)

\begin{tabular}{|c|c|c|c|c|c|}
\hline \multirow[b]{2}{*}{ Fatty acid } & \multirow[b]{2}{*}{ Rat chow } & \multicolumn{4}{|c|}{$\alpha$-Linolenic acid:linoleic acid } \\
\hline & & $1: 7$ & $1: 4$ & $1: 1$ & $1 \cdot 3: 1$ \\
\hline 14:0 & $2 \cdot 7$ & 0.9 & 0.9 & 1.0 & 0.9 \\
\hline $16: 0$ & 19.0 & $26 \cdot 2$ & 24.9 & $28 \cdot 1$ & $24 \cdot 2$ \\
\hline $18: 0$ & $9 \cdot 2$ & $4 \cdot 9$ & 4.7 & $4 \cdot 4$ & 4.8 \\
\hline $20: 0$ & 0.3 & 0.3 & 0.3 & $0 \cdot 4$ & 0.3 \\
\hline $22: 0$ & $\operatorname{tr}$ & 0.3 & 0.3 & $\operatorname{tr}$ & 0.2 \\
\hline Total SFA & $31 \cdot 2$ & $32 \cdot 6$ & $31 \cdot 1$ & $33 \cdot 9$ & $30 \cdot 4$ \\
\hline 14: 1 & $1 \cdot 6$ & $\operatorname{tr}$ & $\operatorname{tr}$ & $\operatorname{tr}$ & $\operatorname{tr}$ \\
\hline $16: 1$ & 1.2 & 0.3 & 0.4 & $0-3$ & 0.1 \\
\hline $18: 1 n-9$ & $24 \cdot 8$ & $34 \cdot 3$ & 32.8 & $34 \cdot 1$ & $27 \cdot 0$ \\
\hline $18: 1 n-7$ & ND & 1.2 & 1.2 & $1 \cdot 2$ & $1 \cdot 3$ \\
\hline $20: 1$ & $0 \cdot 3$ & 0.2 & 0.2 & $0 \cdot 2$ & $0 \cdot 3$ \\
\hline Total MUFA & 27.9 & $36 \cdot 0$ & 34.6 & $35 \cdot 8$ & $28 \cdot 7$ \\
\hline $18: 2 n-6$ & $36 \cdot 0$ & $27 \cdot 2$ & $25 \cdot 3$ & $14 \cdot 6$ & $17 \cdot 1$ \\
\hline $18: 3 n-3$ & $3 \cdot 0$ & 3.7 & 67 & $14 \cdot 3$ & 22.8 \\
\hline $20: 4 n-6$ & $\operatorname{tr}$ & tr & tr & $\operatorname{tr}$ & tr \\
\hline $20: 5 n-3$ & $\operatorname{tr}$ & 0.4 & 0.4 & 0.4 & 0.4 \\
\hline $22: 6 n-3$ & 1.9 & $\operatorname{tr}$ & 0.9 & $1 \cdot 0$ & $0 \cdot 3$ \\
\hline Total PUFA & 40.9 & $31 \cdot 3$ & $33 \cdot 3$ & $30 \cdot 3$ & $40 \cdot 6$ \\
\hline$\alpha$-Linolenic:linoleic & $1: 12$ & $1: 7$ & $1: 4$ & $1: 1$ & $1 \cdot 3: 1$ \\
\hline$n-3: n-6$ & $1: 7$ & $1: 7$ & $1: 3$ & $1: 1$ & $1 \cdot 4: 1$ \\
\hline
\end{tabular}

SFA, saturated fatty acids; MUFA, monounsaturated fatty acids; PUFA, polyunsaturated fatty acids; tr, trace; ND, not detected.

$5 \mathrm{~mm}$-glucose). After the final wash the platelets were resuspended in $1 \mathrm{ml}$ of fresh Tyrode's solution and stored at $-80^{\circ}$ pending methylation.

\section{Analysis of fatty acids}

A modification of the method of Lepage \& Roy (1986) was used to make fatty acid methyl esters. Each platelet preparation was methylated in triplicate. Solvents used in the extraction procedure were supplied by Rhone and Poulenc (Clayton South, Victoria, Australia) and acetylchloride and potassium carbonate by BDH (Poole, Dorset). The methyl esters formed in the benzene layer which was separated from the methanol layer by centrifugation and transferred to GC vials for chromatography. This method achieved $\geqslant 95 \%$ recovery rate for all fatty acids from phospholipids. Methyl esters were assayed in duplicate using flame ionization capillary GC (model 5890A, Hewlett-Packard, North Ryde, Australia) with a fused carbon silica column $(30 \times 0.25 \mathrm{~mm}$ internal diameter) which was coated with cyanopropylphenyl (type DB $225,25 \mathrm{~mm}$ thickness, $25 \% \mathrm{w} / \mathrm{w}$ coating) (J and W Scientific, Folsom, CA, USA). A two-step oven program, $170^{\circ}$ for $2 \mathrm{~min}$ followed by a rise of $10^{\circ} / \mathrm{min}$ to $190^{\circ}$ then $190^{\circ}$ for $1 \mathrm{~min}$ followed by a rise of $5^{\circ} / \mathrm{min}$ to a final temperature of $220^{\circ}$ for $34 \mathrm{~min}$, allowed optimal separation of fatty acid methyl esters.

The fatty acid peaks in the samples were identified by comparing the retention times of the peaks in the sample with those of the fatty acids in GLC 68 fatty acid standard (Nu Check Prep, Inc., Elysian, MN, USA). This standard did not contain 20:5 or 22:5 so the individual methyl esters (Cayman Chemical Company, Ann Arbor, MI, USA) were analysed to determine their retention times. Any peaks that preceded that for 13:0 were not included because the program could not resolve these peaks well. 


\section{Statistical analysis}

The percentages of each fatty acid at the different dietary ratios were compared with each other using ANOVA. A posteriori contrasts were made using the Sheffé $F$ test with the Statview Student computer program (version 1.0, 1991, Abacus Concepts Inc., Berkeley, CA, USA). $P<0.05$ was selected as the level of significance.

\section{RESULTS}

Table 2 shows the platelet fatty acid composition at each of the four dietary ratios. The overall proportion of saturated fatty acids was constant. The monounsaturated fatty acid content showed some variation but $18: 1 n-9$ was unchanged. The relative amounts of total polyunsaturated fatty acids and highly unsaturated fatty acids (i.e. fatty acids with more than three double bonds) were maintained but the total $n-3$ fatty acids increased on the diets with the two highest ALA:LA values. The proportion of EPA doubled and the proportion of AA declined on the $1: 1$ and 1.3:1 diets. ALA doubled at the highest ratio and LA also increased. The platelet EPA:AA value increased on the 1:1 diet and further increased on the $1 \cdot 3: 1$ diet.

\section{DISCUSSION}

The ratio platelet EPA:AA value increased when rats were fed on diets with ALA:LA ranging from $1: 7$ through to $1 \cdot 3: 1$. The platelet phospholipid EPA incorporation was similar on both the $1: 1$ and 1.3:1 diets while platelet AA progressively declined at these ratios. This is in agreement with previous studies of the effect of the dietary ALA:LA value on liver, erythrocyte and lung phospholipids (Hwang et al. 1988; Lands et al. 1990).

Hwang et al. (1988) fed rats on diets with ALA: LA values of $1: 4,1: 2$ and $1: 1$ and found progressive increases in EPA and decreases in AA in plasma, lung and liver phospholipids. It appears that Lands et al. (1990) demonstrated increases in the percentage of EPA in liver and erythrocyte phospholipids up to a dietary ALA: LA of 1.94:1, although no statistical analysis is shown. At a dietary ratio of $2 \cdot 74: 1$ the percentage of EPA declined. In the current study the C18 ALA and LA content of the platelet phospholipids increased on the 1.3:1 diet and, while not significant, a trend to decreasing highly unsaturated fatty acids (fatty acids with more than three double bonds) was observed. Hwang et al. (1988) observed increased percentages of ALA and LA in liver phospholipids at the 1:1 ratio. Whether the increase in the proportion of $\mathrm{C} 18$ fatty acids occurs because the pathways for synthesis of C20 fatty acids are saturated or because the process for acylation of C20 fatty acids into phospholipids is maximal cannot be discerned from the present study.

Lands $e t$ al. (1990) found that a dietary ALA:LA value of approximately 1.3:1 resulted in an erythrocyte EPA:AA value of 0.4 while in the current study the platelet value was $0 \cdot 25$. It may be that there are blood-cell-specific differences but while the membrane $n-3: n$ 6 fatty acids ratio appears to be determined by the dietary ratio, the total proportions will be dependent on the overall supply of fatty acids and the period of consumption. Lands $e t$ al. (1990) fed their rat pups on special diets from conception through to birth, i.e. the mothers had been on modified diets. In the present study, rats were fed on ordinary chow until commencing the test diets. Chow contains predominantly LA which could be deposited in the adipose tissue thereby creating an additional supply of LA to the dietary source, which was not so in the other trial (Lands et al. 1990).

The findings in rats cannot be applied directly to humans. In the current study the dietary ratios were selected because they were within the range that could be achieved in human diets using diet containing $30 \%$ energy as fat with recommended percentages of energy from saturated and polyunsaturated fat (American Heart Association, 1988). In Western 
Table 2. Fatty acid composition ( $\mathrm{g} / 100 \mathrm{~g}$ total fatty acids) of platelets from rats fed on diets with different $\alpha$-linolenic: linoleic acid $(A L A: L A)$ values

(Mean values with their standard errors for three samples, each representing a pool of three rats)

\begin{tabular}{|c|c|c|c|c|c|c|c|c|c|c|}
\hline \multirow{3}{*}{$\begin{array}{l}\text { Time (weeks)... } \\
\text { ALA:LA ... } \\
\text { Fatty acid }\end{array}$} & \multicolumn{2}{|c|}{0} & \multicolumn{8}{|c|}{4} \\
\hline & \multicolumn{2}{|c|}{ Rat chow* } & \multicolumn{2}{|c|}{$1: 7$} & \multicolumn{2}{|c|}{$1: 4$} & \multicolumn{2}{|c|}{$1: 1$} & \multicolumn{2}{|c|}{$1 \cdot 3: 1$} \\
\hline & Mean & SE & Mean & $\mathbf{S E}$ & Mean & SE & Mean & $\mathbf{S E}$ & Mean & $\mathbf{S E}$ \\
\hline Total SFA & $57 \cdot 1$ & $1 \cdot 5$ & $54 \cdot 5$ & 0.4 & $53 \cdot 8$ & 0.6 & $54 \cdot 4$ & 0.6 & $55 \cdot 0$ & 0.9 \\
\hline $\begin{array}{l}18: 1 n-9 \\
\text { Total MUFA }\end{array}$ & $\begin{array}{r}5 \cdot 8 \\
12 \cdot 7\end{array}$ & $\begin{array}{l}0.5 \\
0.6\end{array}$ & $\begin{array}{l}6 \cdot 9 \\
13 \cdot 1^{\text {ab }}\end{array}$ & $\begin{array}{l}0 \cdot 4 \\
0 \cdot 4\end{array}$ & $\begin{array}{c}9 \cdot 5 \\
15 \cdot 0^{\mathrm{b}}\end{array}$ & $\begin{array}{l}1 \cdot 2 \\
1 \cdot 0\end{array}$ & $\begin{array}{c}7 \cdot 8 \\
12 \cdot 7^{\mathrm{ab}}\end{array}$ & $\begin{array}{l}0.5 \\
0.3\end{array}$ & $\begin{array}{c}7 \cdot 5 \\
12 \cdot 6^{\mathrm{a}}\end{array}$ & $\begin{array}{l}0 \cdot 2 \\
0 \cdot 2\end{array}$ \\
\hline $\begin{array}{l}18: 2 n-6 \\
18: 3 n-3\end{array}$ & $\begin{array}{l}7.9 \\
0.4\end{array}$ & $\begin{array}{l}0.2 \\
0.0\end{array}$ & $\begin{array}{l}9 \cdot 5^{\mathrm{a}} \\
0 \cdot 4^{\mathrm{a}}\end{array}$ & $\begin{array}{l}0.3 \\
0.0\end{array}$ & $\begin{array}{l}8 \cdot 8^{\mathrm{a}} \\
0 \cdot 4^{\mathrm{a}}\end{array}$ & $\begin{array}{l}0 \cdot 4 \\
0 \cdot 0\end{array}$ & $\begin{array}{c}10 \cdot 1^{\mathrm{ab}} \\
0 \cdot 6^{\mathrm{a}}\end{array}$ & $\begin{array}{l}0.2 \\
0.3\end{array}$ & $\begin{array}{r}11 \cdot 0^{\mathrm{b}} \\
1 \cdot 1^{\mathrm{b}}\end{array}$ & $\begin{array}{l}0.5 \\
0.1\end{array}$ \\
\hline $\begin{array}{l}20: 4 n-6 \\
20: 5 n-3\end{array}$ & $\begin{array}{r}13 \cdot 1 \\
1.9\end{array}$ & $\begin{array}{l}0.4 \\
0.1\end{array}$ & $\begin{array}{r}14 \cdot 9^{\mathrm{b}} \\
1 \cdot 0^{\mathrm{a}}\end{array}$ & $\begin{array}{l}0 \cdot 6 \\
0 \cdot 0\end{array}$ & $\begin{array}{r}15 \cdot 0^{\mathrm{b}} \\
1 \cdot 2^{\mathrm{z}}\end{array}$ & $\begin{array}{l}0 \cdot 6 \\
0 \cdot 1\end{array}$ & $\begin{array}{c}13 \cdot 3^{\mathrm{ab}} \\
2 \cdot 5^{\mathrm{b}}\end{array}$ & $\begin{array}{l}0.3 \\
0.2\end{array}$ & $\begin{array}{r}11 \cdot 4^{\mathrm{a}} \\
2 \cdot 6^{\mathrm{b}}\end{array}$ & $\begin{array}{l}0 \cdot 6 \\
0 \cdot 1\end{array}$ \\
\hline $\begin{array}{l}22: 5 n-6 \\
22: 5 n-3 \\
22: 6 n-3\end{array}$ & $\begin{array}{l}0.9 \\
1.2 \\
0.5\end{array}$ & $\begin{array}{l}0 \cdot 1 \\
0 \cdot 1 \\
0 \cdot 1\end{array}$ & $\begin{array}{l}1 \cdot 2^{\mathrm{c}} \\
0 \cdot 8 \\
0.7\end{array}$ & $\begin{array}{l}0 \cdot 1 \\
0 \cdot 1 \\
0 \cdot 1\end{array}$ & $\begin{array}{l}1 \cdot 0^{\text {be }} \\
0 \cdot 7 \\
0 \cdot 8\end{array}$ & $\begin{array}{l}0 \cdot 1 \\
0 \cdot 1 \\
0 \cdot 1\end{array}$ & $\begin{array}{l}0 \cdot 7^{\mathrm{ab}} \\
1 \cdot 3 \\
0.8\end{array}$ & $\begin{array}{l}0.1 \\
0.2 \\
0.1\end{array}$ & $\begin{array}{l}0 \cdot 6^{4} \\
1 \cdot 1 \\
0 \cdot 7\end{array}$ & $\begin{array}{l}0 \cdot 1 \\
0 \cdot 2 \\
0 \cdot 1\end{array}$ \\
\hline $\begin{array}{l}\text { Total PUFA } \\
\text { Total HUFA }\end{array}$ & $\begin{array}{l}30 \cdot 2 \\
21 \cdot 9\end{array}$ & $\begin{array}{l}1.0 \\
0.7\end{array}$ & $\begin{array}{l}32 \cdot 4 \\
22 \cdot 4\end{array}$ & $\begin{array}{l}0 \cdot 9 \\
0 \cdot 8\end{array}$ & $\begin{array}{l}31 \cdot 3 \\
22 \cdot 1\end{array}$ & $\begin{array}{l}1 \cdot 2 \\
0 \cdot 9\end{array}$ & $\begin{array}{l}32 \cdot 6 \\
21 \cdot 9\end{array}$ & $\begin{array}{l}0.7 \\
0.7\end{array}$ & $\begin{array}{l}32 \cdot 4 \\
20 \cdot 3\end{array}$ & $\begin{array}{l}0.7 \\
1 \cdot 0\end{array}$ \\
\hline $\begin{array}{l}\text { Total } n-6 \\
\text { Total } n-3 \\
20: 5 / 20: 4\end{array}$ & $\begin{array}{l}21 \cdot 7 \\
4 \cdot 0 \\
0 \cdot 15\end{array}$ & $\begin{array}{l}0.9 \\
0.2 \\
0.01\end{array}$ & $\begin{array}{l}25 \cdot 6 \\
2 \cdot 9^{\mathrm{a}} \\
0 \cdot 07^{\mathrm{a}}\end{array}$ & $\begin{array}{l}0.9 \\
0 \cdot 2 \\
0.00\end{array}$ & $\begin{array}{l}24 \cdot 8 \\
3 \cdot 1^{\mathrm{a}} \\
0 \cdot 08^{\mathrm{a}}\end{array}$ & $\begin{array}{l}1 \cdot 0 \\
0 \cdot 1 \\
0 \cdot 00\end{array}$ & $\begin{array}{l}24 \cdot 1 \\
5 \cdot 2^{b} \\
0 \cdot 18^{b}\end{array}$ & $\begin{array}{l}0.5 \\
0.4 \\
0.01\end{array}$ & $\begin{array}{l}22 \cdot 8 \\
5 \cdot 0^{\mathrm{b}} \\
0 \cdot 25^{\mathrm{c}}\end{array}$ & $\begin{array}{l}1 \cdot 8 \\
0 \cdot 4 \\
0-02\end{array}$ \\
\hline
\end{tabular}

SFA, saturated fatty acids; MUFA, monounsaturated fatty acids; PUFA, polyunsaturated fatty acids; HUFA, highly unsaturated fatty acids ( $>3$ double bonds).

a, $\mathrm{b}, \mathrm{c}$ Mean values within a row not sharing a common superscript letter were significantly different $(P<0 \cdot 05$, Scheffé $F$ test).

* Rat chow was $3 \%$ total energy as fat with ALA:LA of 1:12. The zero time on rat chow was not included in the analysis of variance.

societies all the ratios tested may be considered high as in Australia the dietary ALA:LA may be as low as 1:30 (Truswell et al. 1992). Using rapeseed oil an ALA:LA value of 1:3 can be achieved and this can rise to $1 \cdot 4: 1$ if linseed oil is used. The threshold value of ALA:LA that will result in significant EPA enrichment and an increase in EPA:AA value in human platelets appears to be less than that required by the rats in the current study and lies between 1:7 and 1:3 (Chan et al. 1993). In the current study the platelet EPA:AA value increased from the $1: 4$ to $1: 1$ to $1 \cdot 3: 1$ diet and the maximum platelet incorporation which could be achieved remained undetermined. It was the decline in AA that was responsible for the further increase in EPA:AA value at the 1.3:1 dietary ratio because the EPA concentration was unchanged. The rat demonstrated declines in platelet $\mathrm{AA}$ at the higher ratios, but in humans, AA incorporation is unaffected by ALA intake (Chan et al. 1993; Mantzioris et al. 1995). Thus whether feeding the same ALA:LA values to humans would result in similar persistent increases in platelet EPA:AA is questionable.

In conclusion, the present study establishes that rat platelet phospholipids demonstrate changes in EPA:AA as the dietary ALA:LA value increases. The value at which EPA incorporation becomes maximal in humans requires further investigation as does the value for which EPA:AA in platelets is greatest and has maximal biological advantage.

We wish to thank Drs R. Radcliffe and P. Woodman who advised on the care and surgery of the animals. The work was supported in part by EOI Foods Pty Ltd, Australia. 


\section{REFERENCES}

American Heart Association (1988). Dietary guidelines for healthy American adults. A statement for physicians and other health professionals by the Nutrition Committee American Heart Association. Circulation 77, 721A-724A.

Boudreau, M. D., Chanmugam, P. S., Hart, S. B., Lee, S. H. \& Hwang, D. H. (1991). Lack of dose response by dietary $n-3$ fatty acids at a constant ratio of $n-3$ to $n-6$ fatty acids in suppressing eicosanoid biosynthesis from arachidonic acid. American Journal of Clinical Nutrition 54, 111-117.

Chan, J. K., McDonald, B. E., Gerrard, J. M., Bruce, V. M., Weaver, B. J. \& Holub, B. J. (1993). Effect of dietary $\alpha$-linolenic acid and its ratio to linoleic acid on platelet and plasma fatty acids and thrombogenesis. Lipids 28 , 811-817.

Crawford, M. A., Casperd, N. M. \& Sinclair, A. J. (1976). The long chain metabolites of linoleic acid and linolenic acids in liver and brain in herbivores and carnivores. Comparative Biochemistry and Physiology 54, $395-401$.

de Gomez Dumm, I. N. \& Brenner, R. R. (1975). Oxidative desaturation of alpha-linolenic, linoleic and stearic acid by human liver microsomes. Lipids 10, 315-317.

Dyerberg, J., Bang, H. O. \& Aagaard, O. (1983). $\alpha$-Linolenic acid and eicosapentaenoic acid in man. Lancet $\mathbf{i}$, 199.

Dyerberg, J., Bang, H. O., Stofferson, E., Moncada, S. \& Vane, J. R. (1978), Eicosapentaenoic acid and prevention of thrombosis and atherosclerosis. Lancet ii, 117-119.

Emken, E. A., Adlof, R. O., Radkoff, H., Rohwedder, W. K. \& Gulley, R. M. (1992). Human metabolic studies with deuterated $\alpha$-linolenic acid. Nutrition 8, 213-214.

Emken, E. A., Adlof, R. O., Rohwedder, W. K. \& Gulley, R. M. (1993). Comparison of dietary linolenic and linoleic acid metabolism in man: influence of dietary linoleic acid. In Essential Fatty Acids and Eicosanoids. Invited Papers from the Third International Congress, pp. 23-25 [A. Sinclair and R. Gibson, editors]. Champaign, IL: American Oil Chemists Society.

Herold, P. M. \& Kinsella, J. E. (1986). Fish oils and decreased risk of cardiovascular disease: a comparison of findings from animal and human feeding trials. American Journal of Clinical Nutrition 43, 566-598.

Hwang, D. H., Boudreau, M. \& Chanmugam, P. (1988). Dietary linolenic acid and longer-chain $n-3$ fatty acids: comparison of effects on arachidonic acid metabolism in rats. Journal of Nutrition 118, 427-437.

Lands, W. E. M., Morris, A. \& Libelt, B. (1990). Quantitative effects of dietary polyunsaturated fats on the composition of fatty acids in rat tissues. Lipids $25,505-516$.

Lepage, G. \& Roy, C. C. (1986). Direct esterification of all classes of lipids in a one-step reaction. Journal of Lipid Research 27, 1114-1120.

Mantzioris, E., James, M. J., Gibson, R. A. \& Cleland, L. G. (1995). Differences exist in the relationships between dietary linoleic and $\alpha$-linolenic acids in their respective long chain metabolites. American Journal of Clinical Nutrition 61, 320-324.

Renaud, S. \& Nordoy, A. (1983). 'Small is beautiful': $\alpha$-linolenic acid and eicosapentaenoic acid in man. Lancet ii, 1169.

Sanders, T. A. B. \& Roshani, F. (1983). The influence of different types of $\omega 3$ polyunsaturated fatty acids on blood lipids and platelet function in healthy volunteers. Clinical Science 64, 91-99.

Terano, T., Salmon, J. A., Higgs, G. A. \& Moncada, S. (1986). Eicosapentaenoic acid as a modulator of inflammation. Effect on prostaglandin and leukotriene synthesis. Biochemical Pharmacology 35, 779-785.

Truswell, A. S., Craske, J. D., English, R., Nestel, P. J., Sinclair, A., Lester, I. H. \& Lilburne, A. (1992). The Role of Polyunsaturated Fats in the Australian Diet. Report of the NHMRC Working Party. Canberra: Australian Government Publishing Service.

Weaver, B. J., Corner, E. J., Bruce, V. M., McDonald, B. E. \& Holub, B. J. (1990). Dietary canola oil : effect on the accumulation of eicosapentaenoic acid in the alkenylacyl fraction of human platelet ethanolamine phosphoglyceride. American Journal of Clinical Nutrition 51, 594-598. 